\title{
FOREWORD
}

\section{African Books Collective Its Contribution to African Publishing}

\author{
Mary Jay
}

\section{Introduction}

Today, in the late twentieth century, the decision to publish African authors is still largely though not wholly - taken outside the continent. If we accept the universality of human knowledge and experience, and the desirability of international exchange, does this matter?

The functions of national publishing are manifold. But there are three main beneficial functions. First, the ability of a nation to preserve, develop and communicate its identity, its culture and its heritage is central. In so far as a publishing house has this wider context as the backdrop to its publishing decisions, then those decisions can only be realistically taken within that country. Decisions taken outside the country are bound to be piecemeal, with commercial considerations paramount. An agenda set from outside the continent ultimately denies Africa the right to speak for itself. Second, literacy, books and the reading habit are central to an educated citizenry capable of taking control of their own destiny. And the type of book in this context matters. No national education system should be a fortress and it is surely the right of people in education to benefit from the free flow of intellectual ideas and material. But the crucial word here is 'flow'.

If the flow is disproportionately one-way into Africa, the likelihood is that the citizens at all levels of government - in its broadest sense - will have experienced an education system and a culture with a diluted and distorted sense of the role and development path for their own country. The much documented and most obvious example of this was during the colonial period, when educational curricula were centred, particularly in history, on a Eurocentric colonial interpretation. The role of national publishing in an educational context is not confined to the type of material available; it concerns quantity too. Whilst content matters, so does accessibility. Where national resources are scarce, libraries few in number and under-funded, bookshops few and books often prohibitive in price to the vast majority, and distribution to rural areas virtually non-existent, then irrespective of the content or origin of books, education will suffer or not be available in any meaningful sense.

It is difficult to generalise about the state of the publishing industry in Africa today, since very different conditions may prevail from one country to another and between different groups of countries - each with their own distinctive cultures, traditions, and book trade structures which have developed along different lines and at different paces. Broadly, what follows applies to the sub-Saharan anglophone countries.

Despite the domination, by the $1960 \mathrm{~s}$, of the ex-Africa multinationals, indigenous publishing established itself quite remarkably from around that time. The economic problems which have beset the continent in the 1980s and 1990s, however, took their toll, with the result that publishing has been severely cut back. Infrastructures have deteriorated, 
with particularly poor transport and communications; printing facilities are often poor with, frequently, high tariffs on essential printing equipment; retail outlets and distribution facilities are lacking or inadequate; there is a lack of access to investment capital; and chronic debt problems, and foreign exchange constraints have taken a stranglehold. Educational publishing in some countries is still disproportionately represented by the British and French multinationals, leaving the residual problems for indigenous publishers of access to the backbone of the textbook market. And in other countries, such as Kenya, governments themselves have a monopoly of the textbook market. These economic problems have compounded the problems arising from social conditions: the wide diversity of languages, the high levels of illiteracy, an emphasis on functional reading only, and the inadequacy of libraries. Many parts of Africa suffer a severe book famine. So whilst indigenous publishers established firm footholds in the 1960s and 1970s and were set to face the still formidable challenges, their task became herculean from the 1980s. Through the 1980s, whilst the scale of development was small there was, paradoxically, new innovative enterprise, with books of the highest quality on occasions being produced. These initiatives have been largely in the private sector, and disappointingly few African governments have been supportive of this vital industry. Domination of the textbook market by multinationals in partnership with governments, high tariffs on imported materials, and bureaucracy preventing books crossing borders, are simply the most obvious manifestations. In the $1990 \mathrm{~s}$, the light which had been kept alive is increasingly looking to common solutions on a co-operative basis, and innovative ways to overcome the problems.

\section{African publishing: collective solutions}

African publishers have come together to form two major organisations to tackle different aspects of their common problems.

The African Publishers Network (APNET) was established in February 1992. PanAfrican in scope, its membership is national publishers' associations, and it aims to support communication across borders in Africa, encourage inter-African trading and joint ventures, support the establishment of national publishers' associations where none exist, run training programmes, create a resource centre, and engage in research and lobbying, amongst other activities.

African Books Collective Ltd. was established in 1989 to address one of the many problems mentioned above: the enduring problem for African publishers of the lack of distribution networks - either nationally, regionally, or internationally. If sufficient books can be sold, then a flourishing industry can start to be built. Internationally, there has been great demand, particularly from libraries, for African publications. A small number of commercial distributors, largely serving Europe and the USA, have provided a valuable service, particularly in the acquisition of government documents, 'grey' literature and other ephemera. But for those books bought locally in Africa by dealers, the publisher does not benefit from foreign exchange earnings. For the publisher, trying to process orders direct from overseas, the scale of the bureaucracy in handling export orders and the difficulties of handling small orders often meant the orders went unprocessed. And so, in 1985, a core group of eleven like-minded African publishers came together to see whether they could tackle jointly what they could not tackle individually.

\section{African Books Collective (ABC)}

\section{Objectives}

At that initial meeting, the publishers decided to set up a distribution organisation, wholly owned by themselves, to undertake joint promotion and distribution in Europe, North 
America, and in Commonwealth countries outside Africa. The proposal was met with widespread enthusiasm, and four years of preparatory work, consultation exercises in the African book community, and fund-raising ensued. The objectives were primarily to market and distribute member publishers' English-language books in the main markets outside Africa, in the wider context of the dissemination of African culture and heritage, allowing Africa to speak for itself, and contributing to the international exchange of scholarship, and international understanding. Increased exposure of the wealth of their output would encourage African authors to publish on their own continent and, by earning foreign currency, the publishers would have increased resources to invest in their firms and increase their output.

\section{Council of Management}

Eighteen African publishers founded the company, and it is governed by a Council of Management, comprising elected members from the founding group, and constituted on a broad regional basis. Countries currently represented on the Council are Kenya, Nigeria (2 members), Senegal, South Africa, and Tanzania. The Council of Management is responsible for all policy matters, including the future development and role of ABC. The Council has met formally twice, part-funded by the Commonwealth Foundation. Continuous consultation takes place in the interim, and the Council of Management is provided with regular information, analysis and feedback. It is difficult to raise funding to convene the meetings, but funding is currently being sought to hold a full meeting in 1994 .

\section{Structure}

Each founder member contributed $£ 1,000$ in hard currency towards the start-up costs - no mean achievement in the light of the constraints prevailing, but one which the publishers believed was crucial in order to demonstrate their commitment to the objectives of ABC. The unique nature of $\mathrm{ABC}$ itself, besides being owned and governed by the publishers themselves, lies in its non-profit making nature, enabling the net returns to publishers to be more preferential than is usually available under conventional commercial distribution arrangements. For founder member publishers, ABC retains approximately one-third of net receipts from sales as a contribution towards its operating costs. Member publishers receive sales reports and remittances and $£$ sterling and US Dollar remittances twice-yearly, on the basis of net proceeds from sales. Their stocks are sent to the UK on consignment terms and remain their property until sold. They receive regular analysis and feedback to contribute to their publishing decisions. Because of its trading activities, ABC has been unable to register as a charity with the UK Charities Commission, despite its non-profit making nature. It is a company limited by guarantec, and the members of the Council of Management are the members of the company. Two UK-based directors bear the legal liability.

\section{Funding}

In the light of the non-profit making nature of $\mathrm{ABC}$, and the preferential terms for publishers, donor funding was sought from the outset to support the enterprise. This funding was sought for part-funding of capital and set-up costs, and to meet the shortfall of income over expenditure. The initiative fell squarely within the kind of approach which donors were rightly newly favouring - self-help, benefits to education and literacy within Africa and promotion of awareness outside. It is generally accepted amongst the international 
community that, for example, the right approach to food shortages in Africa is to fund projects leading to self-sustaining development of agriculture and whilst it is imperative to provide aid at times of famine or severe shortage, this must go hand in hand with support for a flourishing agriculture sector. The same could be said to apply to books and publishing: yet $A B C$ too often met the attitude that it was asking for money to be put into the pockets of commercial publishers. The need was, and remains, for support which recognises that considerable investment is needed over a sustained time-span, until such time as the volume of turnover closes the shortfall. A definition surely of 'sustainable development'.

Three donors responded from the outset with support and encouragement: the Ford Foundation, the Swedish International Development Authority (SIDA), and the Norwegian Agency for International Development (NORAD). With this funding, ABC started operations on a small scale in 1990 . The eighteen publishers took the view that too much talk had been expended over too many years at too many conferences, and some practical action must be taken by themselves to start to tackle one part of their problems.

\section{Membership}

Membership is open to all African publishers, although the Council of Management reserves the right to decide on the suitability of applications. The suitability of the list for joint promotion with existing members, among other factors, is of prime concern in deciding on new membership applications. New full members may join for a fee of $£ 500$, and are entitled to $60 \%$ of net returns; associate members do not pay a membership fee, and receive $55 \%$ of net returns; and publishers with only one or two titles for distribution may use the services of $\mathrm{ABC}$ without a fee, and receive $50 \%$ of net returns.

From an initial eighteen founder member publishers in 1989, membership has now more than doubled and has grown to forty-one publishers, from twelve African countries. ABC receives a steady stream of enquiries and applications for membership, which are evaluated against a common set of criteria. A large number have not been accepted for membership, primarily on the grounds of the incompatibility of the list for suitable joint promotion, but there remains a long waiting list of other publishers who are keen to join. In the light of the limited resources available, and rapid expansion in 1992 and 1993, ABC is unlikely to be admitting any further new members in 1994. But it is hoped to expand gradually as resources permit.

Of the current members, over half are African university presses, and other non-profit making academic bodies and research institutes with publishing programmes. The breakdown of membership by country is as follows: Botswana 1, Ghana 4, Kenya 2, Malawi 1, Mauritius 1, Namibia 1, Nigeria 15, Senegal 2, South Africa 2, Tanzania 4, Zambia 1 and Zimbabwe 7. Both South African publishers have been 'oppositional', that is, not collaborating with the apartheid structures and regime which are only now beginning to break down.

\section{Services}

Centralised billing and shipping is provided from one service point, with orders invoiced and shipped within a few days from receipt of order. ABC's orders processing operations are due to be fully computerised in 1994, and this will lead to even more rapid turnaround of orders in the future. Specialist services are also provided: a 'new title information on cards' bibliographic service; standing order and 'blanket' plans for libraries; and a showroom facility in central Oxford displaying (but not selling over the counter) copies of all titles stocked. The displays include member publishers' titles not stocked (mostly older backlist) but for which orders can be forwarded to publishers for direct processing. 


\section{Staff and premises}

ABC's offices are located in the Jam Factory at 27 Park End Street, Oxford. The offices are located outside Africa, because the work of the organisation is to access the markets of the UK, Europe, the USA and other markets outside Africa. It is worth emphasising that, even if problems of communication and infrastructure did not exist in Africa, ABC would still be located somewhere in the markets being targeted - in the same way as a UK or US publisher has offices and distributors in overseas territories. Initially two small rooms were occupied: one used as an office and the other for the showroom display. At the beginning of 1992, ABC expanded into a bigger office suite in the same building, comprising two offices and a showroom. The current complement of staff is two full-time people: an office administrator and promotions assistant; and three part-timers: warehousing manager/shipping; orders processing/customer services; and bookkeeper/credit controller. Occasional part-time staff are employed for administrative support, and relief staff at the warehouse. Two part-time consultants are employed for overall project management, including consultancy and management services, policy guidance, financial planning, and supervision of day-to-day operations.

Warehousing premises are maintained in Burford, some twenty miles from Oxford. Former livestock byres, the $1,800 \mathrm{sq}$. $\mathrm{ft}$. building has been converted and upgraded by the landlord, although the charming Cotswold building and the cobbled floors are not the usual picture conjured up by the word 'warehouse'. After careful consideration, ABC decided not to entrust warehousing to an outside service organisation, but to retain full control of its distribution service and its credit and cash collection. The warehouse now holds a stock inventory of over 108,000 units.

\section{Promotion and marketing}

The number of titles stocked has more than tripled since the start of trading in May 1990, and over 1,100 titles from forty-one member publishers are currently distributed. Some 200 new titles are added to the stock inventory every year, and each title needs individual attention.

The main methods of promotion are extensive direct mail catalogue campaigns and participation in exhibits (described below). Additionally, each title is entered into major bibliographic data bases; title information cards are prepared for all newly-published books, each card providing a short blurb plus full acquisitions data, and these are then mailed direct to key customers; individual flyers are produced and selectively mailed, on particularly outstanding or highly topical titles; and review copies are mailed to the most important African studies periodicals, library journals and other media. Trade promotion is undertaken in the U.K., with visits to key trade outlets, etc. Trade accounts are maintained with some 300 customers, but this market remains very difficult to penetrate and $A B C$ has met with only limited success and the overall turnover from this market is still à small proportion of the total. $\mathrm{ABC}$ is producing, from 1993, a complete annual stocklist, and also issues an occasional $A B C$ Nezsline newsletter. Taking all promotion activities into account, and including also administrative, sales reporting, and warehousing costs, it has been estimated that it costs $\mathrm{ABC}$, pro-rata, a total of about $£ 300$ to take on a new title. For backlist titles it is slightly less.

\section{Diversity}

Each title taken on needs individual attention and nurturing. With the growth in the number of titles handled, the diversity of the lists has increased and widened, and this brings its own problems. Books distributed include a wide spectrum of academic and scholarly publications 
(covering subjects ranging from Adult Education to Zoology); bibliographies and reference resources; a strong list of over 200 titles of African creative writing (fiction, drama, poetry, and critical studies on African literature); a substantial number of children's books; plus general titles on African life and culture. Children's and folklore titles need very different marketing and targeting from that, for example, required for scholarly and academic titles; within the category of scholarly titles, the different disciplines - such as medicine or law require different marketing.

\section{Mainstreaming}

In addition to handling this diversity, $\mathrm{ABC}$ has a mission to 'mainstream' African books to 'de-exotify' them so that they are regarded and treated in the same way as books from the UK, USA or anywhere else. Why, for example, should major booksellers in the UK say that they can't stock our African literature - novels, poetry, drama - because it doesn't fit anywhere or 'there is nowhere to put it'. Why should it not sit on the shelves with the literature of Latin American magic realism, Australian fiction, and indeed the literature from the North? With one or two notable exceptions, bookshops' response is that it is a specialist interest, and would get 'lost' in the main literature shelves, could only go in its own little ghetto somewhere out of the way, and in any case, 'there is no demand'. Despite Africa having three winners of the Nobel Prize for Literature, and a winner of the Booker Prize, most of the great canon of African literature is still marginalised in this way - as in so many others - from the mainstream world cultures.

A major part of the effort to mainstream, is attempting to tap into the vast potential of the US public and school library markets, and making it clear - worldwide - that African books from $\mathrm{ABC}$, warehoused in the UK and available for immediate supply, are as easy to acquire as those from a UK publisher. Some $64 \%$ of ABC sales are currently in the USA. And of total sales, about $70 \%$ are to libraries - academic, institutional, and public. The scale of the task is huge: for example major US publishers mail ten times the quantities of catalogues that $\mathrm{ABC}$ do. It is, however, clear that this is a major development potential for $\mathrm{ABC}$, in particular for the categories of children's, folklore, African heritage and (some) general titles. US public library systems have suffered budget cuts in recent years, and there has been much public lamenting. There is, however, a paradox which makes the outlook rather less depressing than might at first appear. First the number of public libraries is vast, and thus the market left after budget cutbacks still holds great potential. Second, the cuts have been reductions in budgets, rather than freezing of all new purchases. And third, and most interestingly, of the resources available, a greater percentage of the whole is being devoted to the purchase of 'multicultural' materials. This arises from the drive in US library systems to make their libraries more responsive to and reflective of the communities in which they are located. And reinforcing this trend, some libraries are now receiving grants specifically for the purchase of multicultural materials.

At the start of trading, ABC enjoyed some excellent orders from a small number of UK local authority libraries, which recognised that books from Africa were important and relevant for all young people living in a multicultural and multiracial society, including those of African heritage. But alas, the severity of cutbacks in UK public library funding has meant that almost nothing is now acquired by them: the funds simply do not exist. The London Borough of Camden, for example, has just suffered a cut of $£ 54,000$ from its annual budget, including a reduction of $£ 20,000$ for the purchase of new books. ${ }^{1}$

Given that part of the mission of $A B C$ is to change perceptions about African books the politics of language is important. 'Multicultural' has long been used in the UK as meaning

${ }^{1}$ The Bookseller, 20 August 1993, p.13. 
all cultures. The word became commonplace in the US only a few years ago, but was probably more generally used to mean non-Anglo-Saxon culture, in particular, black and hispanic communities. Now, whilst not discredited, the word has been overtaken by 'cultural diversity' as being more specifically about different and equal cultures and terms such as 'culturally inclusive' have been spawned. $A B C$ has been happy to use whatever term is currently used and understood to mean mainstreaming African culture, but it is hard to keep up! Whatever the words are used, many US publishers are newly concentrating on publishing books for the large black population in the US, whose annual purchasing power for books is currently estimated at $\$ 180$ million. ABC therefore also has the hurdle of getting the message across that its books are from Africa, by African authors, and communicate the African experience and heritage; and that this is quite distinct from books published in the USA by American authors, including black authors, for and about the black experience in America.

\section{Catalogues}

ABC catalogues are mailed using the Hans Zell Publishers mailing lists, built up over many years. Hans Zell acts as the senior Consultant to $A B C$ and, through him, $A B C$ has free access to the mailing lists. Additionally, $A B C$ is building up some of its own new specialist lists.

Two main catalogues are issued twice-yearly, and the print runs are usually around 7,000. New (and some backlist) titles are listed with full bibliographic data, and a descriptive blurb. In 1992, a new series of subject catalogues was started. The first one covered all African Languages \& Literature titles; and subsequent catalogues have covered Politics, Economics \& Development; Anthropology, Sociology, and Women's Studies; Medicine \& Health Sciences; History \& Archaeology; Religion \& Theology and Philosophy; and African Law. Subject catalogues are targeted to individual scholars on the mailing lists, and since all titles stocked in the subject area are included, this is very much more convenient for them. It also avoids the expense of mailing all main catalogues to scholars of one discipline only. Individual flyers are issued on particularly important titles, from time to time.

Two glossy four-colour catalogues in substantial print runs have been produced listing children's and folklore titles, African heritage and history, and general titles on African culture such as art, music, cookery, etc. Targeted at the public library systems worldwide, and particularly in the USA, these catalogues present a core range of books for libraries actively developing collections in this field.

\section{Exhibits}

The other main arm of promotion is participation in exhibits and book fairs. ABC has exhibited at meetings of the (US) African Studies Association, the American Libraries Association (ALA), the Black Caucus of the ALA, the Zimbabwe International Book Fair, the London International Book Fair, and the Gothenburg Book Fair. In addition, $A B C$ has participated in joint exhibits at book fairs and scholarly meetings. In 1993, ABC was included in joint exhibits at the Royal African Society annual meeting in Oxford, the Feminist Book Festival in London, the Royal Society of Tropical Medicine \& Hygiene annual meeting in Edinburgh, the 7th General Conference of the European Association of Development Research and Training Institutions (EADI) in Berlin, and the Vitabu Vya Afrika event at the Africa Centre in London.

\section{Other activities}

Whilst ABC's main mission remains the promotion of its member publishers' titles outside 
Africa, the original Mission Statement from the 1985 founding meeting stated that there were two other related areas which the publishers would wish to tackle in due course - an intra-African flow of books, and distribution of French language material. The intention was to establish the main trading mission on a firm and financially secure foothold, before addressing other areas.

\section{Intra-African Book Support Scheme}

The most exciting innovation, and departure from ABC's main mission, came only 15 months after the start of trading. In August 1991 the Intra-African Book Support Scheme (IABSS) was launched.

As is well known and documented, there is very little trade in books between African countries. The problems which affect national and international distribution also apply regionally. Books from Ghana are not seen in Botswana, and books from Namibia are not seen in Nigeria. Indeed the incidence of books crossing neighbouring borders is still negligible. Problems of infrastructure, communication, and foreign exchange constraints, amongst others, inhibit such movements. And this brings losses in more than an economic sense. If the lack of communication of African culture, from Africa to the rest of the world, is to be deplored; then so too is the failure of one culture in Africa to communicate its heritage to another African culture. One of the factors in the cohesion of the continent must be this interchange.

The scheme was launched as a joint project of $A B C$ and the Ranfurly Library Service (now re-named Book Aid International), Britain's largest book aid charity and an independent voluntary organisation which works in partnership with people and organisations in over 70 developing countries to provide relevant books for their needs. For $R L S$, the scheme enabled them 'for the first time ... to make a positive contribution to addressing the root cause of the book famine in Africa, by supporting the African publishing industry'. And for $A B C$, the scheme enabled the task of an intra-African flow of books to be tackled very much sooner than anticipated, while maintaining the existing structure of the organisation.

Charity Projects (UK), which raises money through the Comic Relief appeal, made a grant of $£ 50,000$ to RLS for the purchase of ABC books for supply to selected African major academic libraries which had been unable to purchase African books published outside their own country because of the chronic foreign exchange constraints. One library in each of twelve African countries was a recipient. Each selected titles from ABC catalogues, and RLS shipped the books through free shipping facilities. DANIDA, the Danish Government's Coordinating Committee for Cultural Cooperation with Developing Countries, funded ABC directly to supply the same libraries with one copy of each new ABC-distributed title thereafter. The libraries filled out Standing Order profile forms stipulating the types of books they wished to receive. And this generous funding has continued since 1991 .

When the scheme was launched, the ABC membership stood at twenty publishers, who benefited from the Charity Projects funding. As new funding is secured, all subsequent member publishers titles are also included in donations.

With the launch of IABSS, a significant component of African-published material has been included in a book donation scheme, perhaps for the first time. The scheme enables students and scholars from one part of Africa to gain access to African publishing from other parts of the continent; addresses the 'book famine' in Africa; and promotes an intra-African flow of books. It is recognised that there is a certain irony in books being shipped to the UK from all parts of Africa, only to be shipped back again! However, the reality is that it is simple, practical and efficient to operate the scheme in this way; and that it would be very difficult to organise within Africa in current conditions. It is clearly desirable, however, that one day the scheme should be administered from within Africa, but when the day comes that books 
from all over Africa can be warehoused at one point, the likelihood is that the scheme itself will no longer be necessary.

The Children's Book Support Scheme was launched in March 1992 as a component of IABSS. With general funding from the Ministry for Development Cooperation of the Netherlands Government, the scheme was similarly organised, but addressed the needs of children's libraries in Africa. Up to 188 copies of 99 different children's books, from thirteen ABC member publishers, were supplied to children's libraries, rural community centres, orphanages and primary schools in eight African countries. A total of over 13,000 units were supplied through RLS, who arranged shipping to National Library Services and other distributors (with which they have already established long term links) which then provided effective distribution networks both to and within each of the recipient countries. A further grant has been made to the CBSS by the Dutch Government for 1993.

In 1991 and 1992 the three parts of LABSS contributed remittances to member publishers of some $f 66,000$ in hard currency.

The Swedish Agency for Research Cooperation with Developing Countries (SAREC) has provided a grant in 1993 direct to ABC, towards the development of IABSS. Three of the libraries in the original scheme have been allocated additional funding for selecting books from ABC, and two additional libraries - in Eritrea and Mozambique - have been funded to make selections. This funding has been renewed for 1994-1996.

From an expression of the ideal in 1985, the hope of promoting an intra-African flow of books has become a reality. The benefits to member publishers themselves have been great, contributing to greater publishing activity, and they are all very keen to secure funding to extend the scheme further. For ABC itself, the approximately one-third of net income retained from the sales has made a significant contribution to core-funding, enabling the minimum necessary complement of staff to be employed, and contributing to overheads. Whilst the need for core-funding is paramount (since this is not the favoured funding of donor organisations), considerable energy is being devoted to trying to secure further funding for IABSS, which itself makes a contribution to ABC's own self-generated revenue.

\section{French-language material}

As originally intended, $\mathrm{ABC}$ stocks only English-language material. But the publishers believed it would be right to stock books in the other languages of Africa when the firm base of English-language distribution was established. For African language material, it was recognised that the market was very small, and could not be embarked on as other than a loss-making operation. And thus no consideration should be given to this until such time in the future as the profitability of the trading operation could subsidise African language distribution. It was not thought that the potential for Portuguese language distribution was great, but that there would be potential for French language distribution. The publishers had in mind here also the desirability of breaking down the 'anglophone' and 'francophone' divisions. One of the founder members was the Council for the Development of Economic \& Social Research in Africa (CODESRIA), based in Senegal, and with a publishing arm presenting research findings in books produced in both English and French. ABC distributes their English language titles. In 1993, Environmental Development Action in the Third World (ENDA), also based in Senegal, joined ABC. These two prestigious research institutions provide a bridge, and symbolise the importance of breaking down the artificial barriers inherited from the colonial spheres of power and continuing influence. But as to actual distribution of French language material, the time has not come, and may not do so. Due to inherited colonial structures, and the very different models of 'independence' in the English and French/Belgian ex-colonies, the publishing structures are very different, and selling of francophone African books is governed by different market forces. The ties in the 
francophone countries with publishing in France are still very strong, and few francophone African publishers are genuinely autonomous. Additionally, the traditional pattern in the francophone countries has been for distribution to be handled independently in France. Added to this, the major problem confronting anglophone publishers are the fluctuating, and deteriorating, exchange rates; whereas the francophone countries have the bulwark of the CFA system which is tied to the French franc.

\section{$A B C$ 's own first publication}

Working in the wider context of dissemination of information about African books and writing, and support for autonomous African publishing, $\mathrm{ABC}$ engages in related supportive activities. To further these objectives, material will occasionally be published. The first publication, in June 1993, was the African Publishers Networking Directory and 'Names $\mathcal{E}$ Numbers'1993/94 (ISBN 0952126907). A reference guide and networking tool for publishers and the book communities in Africa - and for Africana librarians and other interested in the book industries and book development in Africa - the 64pp. directory provides full names and addresses, telephone, and fax/telex numbers of the major and/or most active book publishers in Africa today. Other listings include African book trade organisations supporting African publishing, assistance programmes, book charities active in Africa, and more. The directory is free to African publishers, librarians, booksellers, and African writers. A charge of $£ 10 / \$ 20$ is made to others, as a contribution towards subsidising its free availability within Africa.

\section{Sales}

ABC's sales have steadily increased, and with the benefit of IABSS, reached some $£ 160,000$ in 1992, of which about $£, 100,000$ in hard currency was remitted back to African publisher members. $A B C$ is currently trading with almost 400 booksellers and library suppliers, over 500 library accounts, and some 300 individual book buyers, in 69 countries. Nonetheless, with worldwide recession, current market conditions are very different to those prevailing in the planning stages in the mid-1980s, and the somewhat optimistic scenarios have, not surprisingly, failed to materialise. The business plans' aim to keep increases in overheads to no more than $71 / 2 \%$ annually, has been difficult to achieve in the light of the rapid expansion in membership and in the inventory. $A B C$ is currently on target for a year-to-year growth rate in turnover of about $30 \%$ (excluding IABSS sales), although this is likely to become increasingly difficult in current market conditions. Annual turnover in the region of currently $£ 130,000-£ 160,000$ might be considered modest, but it has been generated from scratch, and such a level of export sales and hard currency earnings has never before been achieved by African publishers.

\section{Future needs}

ABC's major expenditures and overheads are for personnel; rent for office and warehouse premises; and substantial investment in promotion and marketing each year to promote the stock inventory of over a thousand titles, (plus some 200 new titles annually). At the current level of annual recurrent expenditure (without provision for any further capital expenditures), ABC would need to generate sales of at least $£ 470,000 / \$ 740,000$ to match expenditures and reach break-even point. With a list of relatively low-priced books with an average retail price of around $£ 8.50 / \$ 13$, such turnover figures - even with the support of the most aggressive and extensive promotion - cannot be achieved at this time.

It remains an ultimate goal to achieve self-sufficiency, but from the experience of three 
years' trading, it is clear that any hope of early self-sufficiency is unrealistic. ABC faces the same difficult market conditions as all publishers, but given its non-profit making nature, its wider objectives, and its consequent structure, it does not have recourse to the options open to commercial publishers. With current trading conditions, brought about by the recession, these available commercial responses include shorter print runs and very substantial price rises, or the decision that it is not commercially viable to publish a title which in better conditions might have been taken on. But such options fly in the face of the objectives of $A B C$. Thus the need for donor funds to make up for substantial shortfalls between self-generated income retained by $A B C$ on the one hand, and annual recurrent expenditure on the other, will remain.

There is little room for manoeuvre to cut overheads, and whilst $\mathrm{ABC}$ will continue to operate with strictly business-like efficiency, maintaining tight control on expenditure, and maximising all sales potentials, self-sufficiency cannot realistically be expected in the foreseeable future.

\section{Donor funding}

In 1992 direct grants were received from five agencies, in addition to separate support for IABSS. Unesco's grant represented $4.3 \%$ of total 1992 annual expenditure, CODE (Canada) $6 \%$, DANIDA $10 \%$, SIDA $11.2 \%$, and generous support from the Rockefeller Foundation for promotion and marketing, including exhibit participation, represented some $40 \%$. These agencies have renewed support for 1993, and additionally SAREC has made a direct grant.

Donor organisations have recognised, in principle, the need for long-term support for $A B C$. At the inception of $A B C$, the publishers were working in something of a void, with approaches by donors to some extent fragmented, and with only a small number concentrating on African publishing as such. There has, however, been a transformation over recent years, with the establishment of an informal group of donors working together in the context of support for African publishing, and known as the 'Bellagio Group'. This Group arose from a conference organized by the Rockefeller Foundation - at their conference centre in Bellagio, Italy - on publishing development in the Third World, including Africa. ${ }^{2}$ Four of the African publishers at the conference were also members of ABC's Council of Management, and the $A B C$ concept was placed firmly in the wider picture of appropriate and coordinated approaches to support for African publishing. The publishers now have the security of this context and understanding, and the understanding too that it will be many years hence before ABC can hope to break even, despite an encouraging and steady growth in sales and turnover of some $30 \%$ annually. But as the Group as such does not guarantee collective support for $\mathrm{ABC}$, the daunting prospect of annual grant decisions is still being faced. With the scale of activities and trading now undertaken, and the responsibilities to publisher members and staff, the concern is now to try and secure longer commitments than one-year funding. SIDA, SAREC and CODE have already recognised this need for secure planning, and have made two- and three-year grants.

\section{ABC's success to date}

African Books Collective has achieved a considerable measure of success over a short period of time, but this success cannot be evaluated in terms of sales figures alone. Whilst the

2

2 The papers presented at this conference were published in Publishing and Development in the Third World, ed. Philip G. Altbach (London: Hans Zell Publishers, 1992). 
African Books Collective initiative represents a significant reversal of historical trading directions, ABC is doing a great deal more than merely selling books. It is actively promoting and disseminating African scholarship, African writing, and African cultural identity, and also contributing towards a better understanding of the ethnic, cultural and religious diversity of Africa - which in turn promotes a positive image of Africa. Moreover, ABC's activities have led to enhanced opportunities for publishing and writing in Africa.

The main concrete achievements in $\mathbf{1 9 9 3}$ have covered activities at the heart of the main objectives, and in furtherance of wider objectives. Seven new member publishers were admitted, 220 new titles were actively promoted, and eighty new backlist titles taken on. $60-65 \%$ of net income received was remitted to member publishers at six-monthly intervals, in hard currency, helping member publishers to survive and grow under the current difficult trading conditions. Extensive promotion and marketing activities have been undertaken, including a variety of catalogue mailings to some 32,000 recipients. Promotion and displays have been provided for African-published books at exhibits at major library, booktrade, and professional and academic meetings. African-published books have been supplied to African academic and public libraries through the IABSS. The African Publishers Networking Directory was compiled, published, and distributed free to the African book community. And ABC organised a roundtable on African publishing at the (US) African Studies Association's 36th annual meeting in Boston.

Member publishers have recently evaluated how the formation of $\mathrm{ABC}$ has affected their publishing programmes, and amongst positive points they have made are the following direct quotations, illustrating their awareness of its tangible benefits:

'... ABC is turning out to be a lot more important as a distribution outlet than $I$ ever imagined . . we are now able to confidently assure our authors of international promotion and distribution. And I am glad to say that the mention of $A B C$ has increased their confidence in our ability to provide this service.'

Henry Chakava, Managing Director, East African Educational Publishers, Nairobi

'The ABC letter enclosing our cheques for Period V were very pleasing and provided a great relief in an otherwise harsh economic environment. ABC earnings have contributed in no small way to our rising annual output ... it is also clear that our books have received greater exposure to the international markets ... authors who are now receiving payment in hard currency for royalties for their titles sold by $A B C$ are very happy and now feel encouraged to write'. Victor Nwankwo, Managing Director, Fourth Dimension Publishing Co., Enugu, Nigeria

'Since joining ABC our export sales have increased by about $200 \%$ while the export promotion and distribution costs have decreased by about $53 \%$. The increased export sales revenue, which is paid in hard currency, has facilitated increased royalty payments to our authors and stimulated greater publishing activity in our books. There is no doubt that the ABC service has increased the overseas exposure and review coverage of our publications, and this development has made our existing authors happier, and has also attracted a greater number of potential authors.'

Prof. Olatunde Olatunji, Chairman, Ibadan University Press, Ibadan

'Trading with $\mathrm{ABC}$ has benefitted our company in Ghana ... now we have enough funds to employ two more hands ... the regular remittances from $\mathrm{ABC}$ are enabling us to expand our publishing programme'.

Woeli Dekutsey, Woeli Publishing Services, Accra

\section{Conclusion}

African Books Collective, whilst primarily a marketing and distribution enterprise, has been described as a 'tuming of the tide' for African publishing, and the start of a reversal of historical trading patterns. Wide support and understanding is sought for ABC's work, and the active participation of all those who can encourage the acquisition of African books whether librarians, academics, institutions of learning, booksellers, schools, or community organisations. There is much work to be done in the future. Membership can be expanded; more services offered to publishers, including further help in facilitating and acting for them 
xviii

in rights negotiations; and in due course it will make sense to have a distribution outlet in North America. The Council of Management will be meeting in 1994 to consider current and future work. The hope is that with continued, and possibly new, support of donor organisations, the publishers will have the capacity to carry the work forward. 